\title{
CXCR3 May Help Regulate the Inflammatory Response in Acute Lung Injury via a Pathway Modulated by IL-10 Secreted by CD8+CD122+ Regulatory T Cells
}

\author{
Li Nie, ${ }^{1,4}$ Wei Wu, ${ }^{2}$ Zhibing Lu, ${ }^{3}$ Gangyan Zhu, ${ }^{1}$ and Juan Liu ${ }^{1}$
}

\begin{abstract}
The aim of this study is to investigate the role of CXCR3 and IL-10 in lipopolysaccharide (LPS)-induced acute lung injury (ALI). ALI was induced by LPS injection $(10 \mathrm{mg} / \mathrm{kg})$ via the tail vein in $\mathrm{C} 57 \mathrm{BL} / 6$ mice. Mice were sacrificed after 2 or $12 \mathrm{~h}$ to examine the levels of inflammatory cytokines in bronchoalveolar lavage fluid (BALF) and histopathologic assessments. At $12 \mathrm{~h}$ after LPS injection, mice exhibited more severe lung infiltration by $\mathrm{CD} 8+\mathrm{T}$ cell and less infiltration by $\mathrm{CD} 8+\mathrm{CD} 122+$ regulatory $\mathrm{T}$ cells than at $2 \mathrm{~h}$ after LPS challenge or in the control (mice not exposed to LPS). At $12 \mathrm{~h}$, IFN- $\gamma$, CXCR3, and CXCL10 were significantly higher in the lungs. IL-10 in the lungs was significantly lower. CXCR3 may help to recruit CD8+ T cells and promotes IFN- $\gamma$ and CXCL10 release. Such effects could be inhibited by IL-10 secreted by CD $8+\mathrm{CD} 122+$ regulatory T cells.
\end{abstract}

KEY WORDS: acute lung injury; CXCR3; CD8 + CD122+ regulatory T cells; interleukin-10.

\section{INTRODUCTION}

Acute lung injury (ALI) and acute respiratory distress syndrome (ARDS) are frequent complications in patients with burns, trauma, and sepsis, and they are associated with high rates of morbidity and mortality [1]. Infection or mechanical injury triggers a generalized inflammatory response involving various inflammatory cells and pro-inflammatory mediators. In particular, several studies suggest that the chemokine receptor CXCR3, which is expressed primarily on activated T lymphocytes, natural killer (NK) cells and some epithelial cells, can trigger an inflammatory response cascade at sites of ALI by recruiting CD8+ T cells and promoting release of proinflammatory interferon- $\gamma(\mathrm{IFN}-\gamma)$ and chemokine CXCL10 [2].

\footnotetext{
${ }^{1}$ Department of Geriatrics, Renmin Hospital of Wuhan University, 238, Jiefang Road, Wucang, Wuhan, 430060, China

${ }^{2}$ Clinical Laboratory Department, Renmin Hospital of Wuhan University, Wuhan, China

${ }^{3}$ Department of Cardiology, Renmin Hospital of Wuhan University, Wuhan, China

${ }^{4}$ To whom correspondence should be addressed at Department of Geriatrics, Renmin Hospital of Wuhan University, 238, Jiefang Road, Wucang, Wuhan, 430060, China. E-mail: bywaters@163.com
}

The body is capable of mitigating the inflammation in ALI by releasing anti-inflammatory mediators at injury sites, leading investigators to examine how the disbalance between pro- and anti-inflammatory factors may drive ALI and may be manipulated for therapeutic effects [3-5]. For example, interleukin-10 (IL-10) secreted by CD8+CD122+ regulatory $\mathrm{T}$ cells has been shown to inhibit $\mathrm{CD} 8+\mathrm{T}$ cells and reduce inflammation in various inflammatory diseases [6]. However, whether $\mathrm{CD} 8+\mathrm{CD} 122+$ regulatory $\mathrm{T}$ cells and IL-10 regulate CXCR3 activity in ALI has not been reported.

In the current study, we examined whether CXCR3 could interact with IL-10 secreted by CD8+CD122+ regulatory $\mathrm{T}$ cells in a mouse model of ALI induced by lipopolysaccharide (LPS) exposure.

\section{MATERIAL AND METHODS}

\section{Mouse Model of ALI}

Healthy male C57BL/6 mice aged 10-12 weeks and weighing 20-22 g (SJA Laboratory Animals, Hunan, China)were randomly divided into a control group $(n=8)$ and two ALI groups ( $n=8$ each). At baseline, control mice 
were injected in the tail vein with $1 \mathrm{ml}$ saline, while ALI mice were injected with $10 \mathrm{mg} / \mathrm{kg}$ lipopolysaccharide (Sigma, Beijing, China) dissolved in $1 \mathrm{ml}$ saline. One group of ALI mice was sacrificed by pentobarbital overdose at $2 \mathrm{~h}$ after injection, while the other ALI group as well as the control group was sacrificed at $12 \mathrm{~h}$ after injection.

All experiments were conducted according to international and institutional guidelines for animal care, and the study protocol was approved by the Research Ethics Committee of Renmin Hospital, Wuhan University.

\section{Lung Tissue Histology}

The lower lobe of the left lung was removed, inflated to $250 \mathrm{mmH}_{2} \mathrm{O}$ with $10 \%$ formal in, fixed overnight, embedded in paraffin, and sectioned to a thickness of $5 \mu \mathrm{m}$. Sagittal sections were stained with hematoxylineosin (HE) for histopathologic assessments under a light microscope (Olympus, Japan) by an experience pathologist blinded to treatment conditions.

\section{Harvesting of Bronchoalveolar Lavage Fluid}

Tracheas of sacrificed animals were intubated with a 20-gauge catheter. Bronchoalveolar lavage fluid (BALF) was collected by flushing twice with $0.8 \mathrm{~mL}$ of ice-cold phosphate-buffered saline (PBS). A total injected volume of $1.5 \mathrm{~mL}$ was recovered in $>95 \%$ of mice. The recovered BALF was centrifuged at $1500 \mathrm{rpm}$ for $5 \mathrm{~min}$ at $4{ }^{\circ} \mathrm{C}$, and the supernatant was stored at $-70^{\circ} \mathrm{C}$ for subsequent assay of cytokines and chemokines. Total cells were counted on a hemocytometer. For differential cell counting, cells were spun onto glass slides, fixed, and stained with Diff-Quik reagents (Beijing Chemical Works, Beijing, China). Numbers of macrophages, neutrophils, and lymphocytes per 400 cells were determined based on morphology.

\section{Antibody Labeling of Cells from BALF}

BALF cells $\left(2 \times 10^{7} / \mathrm{mL}\right)$ resuspended in $50 \mu \mathrm{L}$ PBS were incubated for $15 \mathrm{~min}$ on ice with $10-\mu \mathrm{L}$ blocking buffer $(1 \mu \mathrm{L}$ blocking antibody $\mathrm{Fc}+9 \mu \mathrm{L}$ PBS containing $2 \%$ bovine serum albumin (Sigma)). Cells were washed once with PBS and then incubated for $1 \mathrm{~h}$ on ice with $50 \mu \mathrm{L}$ FITC-conjugated anti-CD122 antibody (Sigma), PE-conjugated anti-CD8 antibody (Sigma), or control mouse IgG2b (Sigma). Cells were washed twice with PBS, then fixed in PBS containing $2 \%$ formalin. Cells were sorted by flow cytometry on a FACScan cytometer (BD, Franklin L, New Jersey, USA).

\section{Determination of Cytokine and Chemokine Levels in BALF Using Enzyme-Linked Immunosorbent Assay (ELISA)}

Commercial ELISA kits (R\&D Systems, Minneapolis, MN, USA) were used to measure concentrations of IFN- $\gamma$, CXCR3, CXCL10, and IL-10 in BALF.

\section{Quantitation of Cytokine and Chemokine mRNA Levels in Lung Tissue}

Total cellular RNA was isolated using TRIzol reagent (Invitrogen, Carlsbad, CA, USA) from sections of lung tissue weighing $100 \mathrm{mg}$. Total RNA was reverse-transcribed using the Reverse Transcription Kit (Invitrogen), and the resulting cDNA was subjected to PCR to measure levels of mRNAs encoding IFN- $\gamma$, CXCR3, CXCL10, or IL-10 (Table 1). Transcript levels were quantified using the $\Delta_{\mathrm{T}}$ method, in which $C_{\mathrm{T}}$ refers to the threshold number of cycles and $2^{-\triangle \Delta C T}$ refers to the amount of target transcript relative to the endogenous control $\beta$-actin.

\section{Statistical Analysis}

Data are expressed as mean $\pm \mathrm{SD}$. Comparisons between two groups were carried out using the nonparametric two-tailed $t$ test. Possible correlations between different factors were explored across all three groups using Pearson correlation analysis. All analyses were performed using SPSS19.0 (IBM, Chicago, IL, USA). $P<0.05$ was considered statistically significant.

\section{RESULTS}

\section{Lung Histopathology in LPS-Induced ALI}

Lung tissue from control mice appeared normal with no significant signs of inflammation or of inflammatory cells in the pulmonary alveolus (Fig. 1). Tissue sections from ALI mice showed much greater accumulation of leukocytes in the pulmonary parenchyma and peribronchus at $12 \mathrm{~h}$ than at $2 \mathrm{~h}$ or in mice not exposed to LPS.

\section{Infiltration of Inflammatory Cells into the Airways and Lungs}

To determine whether LPS affects the infiltration of inflammatory cells into airways, we measured the sizes of different $\mathrm{T}$ cell populations in BALF. Populations of various inflammatory cells, including leukocytes, lymphocytes, neutrophils, and macrophages were larger in BALF from ALI 
Table 1. PCR Primers and Annealing Temperatures for Quantitation of Cytokine and Chemokine Transcript Levels

\begin{tabular}{|c|c|c|c|c|}
\hline Target & $\mathrm{F} / \mathrm{R}$ & Sequence $\left(5^{\prime}\right.$ to $\left.3^{\prime}\right)$ & $\operatorname{Tm}\left({ }^{\circ} \mathrm{C}\right)$ & Product (bp) \\
\hline \multirow[t]{2}{*}{ IFN- $\gamma$} & $\mathrm{F}$ & CCCCGCAGTATTGATGAGTT & \multirow[t]{2}{*}{56} & \multirow[t]{2}{*}{194} \\
\hline & $\mathrm{R}$ & TTGGAATAGTTGCCCGAGTC & & \\
\hline \multirow{2}{*}{ CXCR3 } & $\mathrm{F}$ & ACTACGATCAGCGCCTCAAT & \multirow[t]{2}{*}{56} & \multirow[t]{2}{*}{163} \\
\hline & $\mathrm{R}$ & CCTCTGGAGACCAGCAGAAC & & \\
\hline \multirow[t]{2}{*}{ CXCL10 } & $\mathrm{F}$ & AAGTGCTGCCGTCATTTTCT & \multirow[t]{2}{*}{56} & \multirow[t]{2}{*}{186} \\
\hline & $\mathrm{R}$ & GTGGCAATGATCTCAACACG & & \\
\hline \multirow[t]{2}{*}{ IL-10 } & $\mathrm{F}$ & CCAAGCCTTATCGGAAATGA & \multirow[t]{2}{*}{56} & \multirow[t]{2}{*}{162} \\
\hline & $\mathrm{R}$ & TTTTCACAGGGGAGAAATCG & & \\
\hline \multirow[t]{2}{*}{$\beta$-actin } & $\mathrm{F}$ & CACGATGGAGGGGCCGGACTCATC & \multirow[t]{2}{*}{56} & \multirow[t]{2}{*}{240} \\
\hline & $\mathrm{R}$ & TAAAGACCTCTATGCCAACACAGT & & \\
\hline
\end{tabular}

$F$ forward, $R$ reverse

mice at $12 \mathrm{~h}$ than in BALF from the other two groups, indicating a stronger inflammatory response. Populations of leukocytes and neutrophils were significantly higher in BALF from ALI mice at $2 \mathrm{~h}$ than in BALF from control mice (Table 2).

\section{Populations of CD8+ T Cells and CD8+CD122+ T Cells in Airways and Lung Tissue}

The percentage of CD8+ T cells in both BALF and lung tissue was significantly higher in ALI mice at $12 \mathrm{~h}$ than in either control mice or ALI mice at $2 \mathrm{~h}$. Conversely, the percentage of $\mathrm{CD} 8+\mathrm{CD} 122+$ regulatory $\mathrm{T}$ cells was lowest in ALI mice at $12 \mathrm{~h}$, higher in ALI mice at $2 \mathrm{~h}$, and highest in control animals (Fig. 2, Table 3). Percentages of $\mathrm{CD} 8+\mathrm{CD} 122+$ regulatory $\mathrm{T}$ cells correlated negatively with percentages of CD8 + T cells in both BALF $(r=-0.797)$ and lungs $(r=-0.994)$.

\section{Levels of Inflammatory Cytokines and CXCL10 in BALF}

BALF from ALI mice at $2 \mathrm{~h}$ contained significantly higher protein levels of CXCR3, CXCL10, and IFN- $\gamma$ than BALF from the control group, and the levels of all three proteins were significantly higher at $12 \mathrm{~h}$ than at $2 \mathrm{~h}$ (Fig. 3, Table 4). Conversely, IL-10 concentration was significantly lower in BALF from ALI mice at $12 \mathrm{~h}$ than in ALI mice at $2 \mathrm{~h}$; the concentration was in turn significantly lower in ALI mice at $2 \mathrm{~h}$ than in control animals. Levels of CXCR3 protein correlated negatively with levels of IL-10 protein in BALF $(r=-0.969)$.

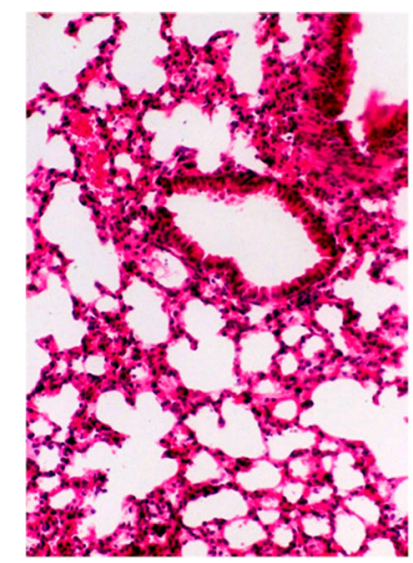

Control

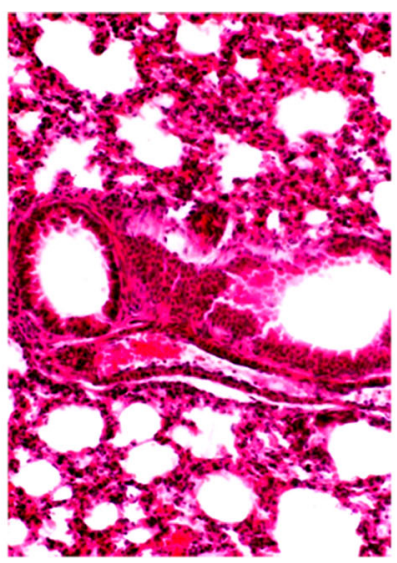

LPS $2 h$

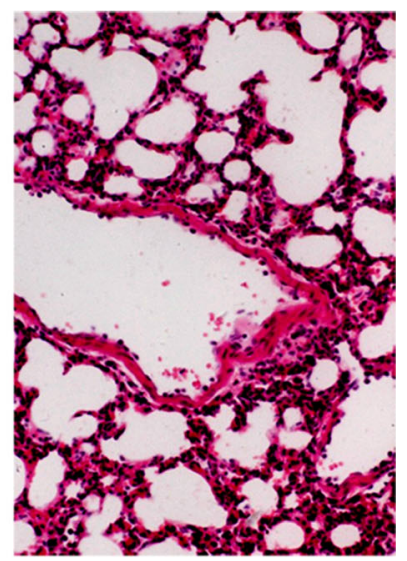

LPS 12h

Fig. 1. Representative photomicrographs of lung tissues stained with hematoxylin-eosin from control mice and mice with acute lung injury harvested at 2 and $12 \mathrm{~h}$ after lipopolysaccharide (LPS) injection. Magnification, $\times 400$. 
Table 2. Inflammatory Cell Counts in Bronchoalveolar Lavage Fluid from Control Mice and Mice with Lipopolysaccharide-Induced Acute Lung Injury (ALI) after 2 or $12 \mathrm{~h}$

\begin{tabular}{lllr}
\hline Cell type & Control $(n=8)$ & ALI at $2 \mathrm{~h}(n=8)$ & ALI at $12 \mathrm{~h}(n=8)$ \\
\hline Leukocytes, $\times 10^{5}$ & $2.03 \pm 0.51$ & $5.88 \pm 0.89^{* \#}$ & $39.90 \pm 4.00^{*}$ \\
Lymphocytes, $\times 10^{3}$ & $0.33 \pm 0.01$ & $0.34 \pm 0.01^{\#}$ & $0.36 \pm 0.01^{*}$ \\
Neutrophils $\times 10^{2}$ & $0.14 \pm 0.03$ & $0.29 \pm 0.03^{* \#}$ & $0.43 \pm 0.05^{*}$ \\
Macrophages, $\times 10^{2}$ & $0.82 \pm 0.06$ & $0.83 \pm 0.05^{\#}$ & $0.99 \pm 0.06^{*}$ \\
\hline
\end{tabular}

Results are expressed as mean $\pm \mathrm{SD}$

${ }^{*} P<0.05$ vs control group; ${ }^{\#} P<0.05$ vs ALI at $12 \mathrm{~h}$

\section{Levels of Cytokine and Chemokine mRNA in Lungs}

Consistent with our analyses of protein levels in BALF, levels of mRNA encoding CXCR3, CXCL10 and IFN- $\gamma$ were markedly higher in lungs of ALI mice at $12 \mathrm{~h}$ than at $2 \mathrm{~h}$ or in mice not exposed to LPS (Fig. 4). Levels of CXCR3 mRNA were significantly higher in ALI mice at $2 \mathrm{~h}$ than in healthy animals. Also consistent with the BALF analyses, levels of IL-10 mRNA were highest in the control group, lower in the ALI mice at $2 \mathrm{~h}$, and lowest in the ALI mice at $12 \mathrm{~h}$. Levels of CXCR3 mRNA correlated negatively with levels of IL-10 mRNA in lung tissue $(r=-0.664)$.

\section{DISCUSSION}

Using a mouse model of LPS-induced ALI, we show that injury progression is associated with decreased expression and secretion of IL-10 and increased expression of
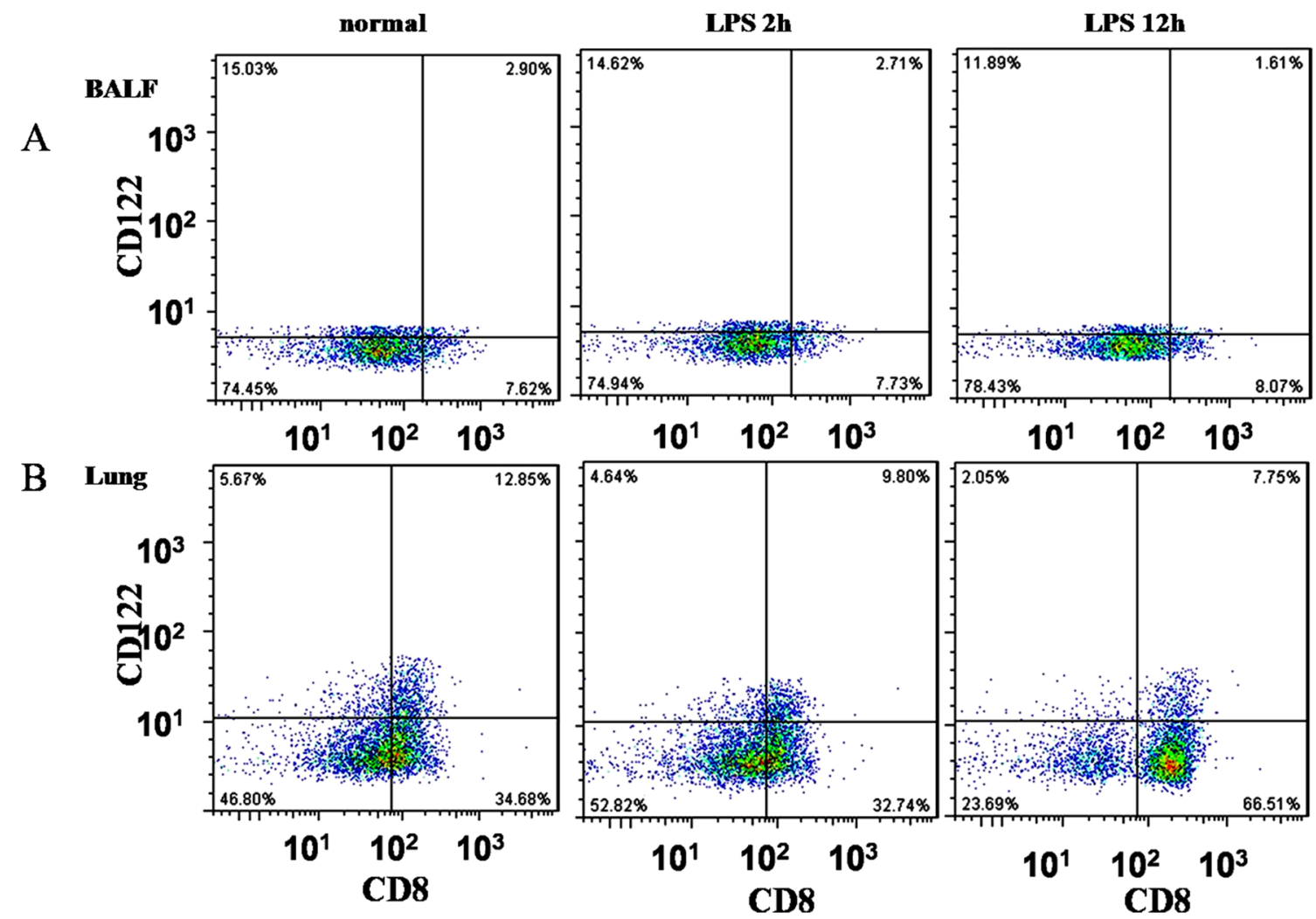

Fig. 2. Infiltration of the a airways and $\mathbf{b}$ lungs by CD8+ T cells and CD8+CD122+ T cells in control mice and mice with acute lung injury at 2 and $12 \mathrm{~h}$ after lipopolysaccharide (LPS) injection. 
Table 3. Percentages of $\mathrm{CD} 8+$ and $\mathrm{CD} 8+\mathrm{CD} 122+\mathrm{T}$ cells in Bronchoalveolar Lavage Fluid and Lung Tissue from Control Mice and Mice with Lipopolysaccharide-Induced Acute Lung Injury (ALI) After 2 or $12 \mathrm{~h}$

\begin{tabular}{llll}
\hline Cell type & Control $(n=8)$ & ALI at $2 \mathrm{~h}(n=8)$ & ALI at 12 h $(n=8)$ \\
\hline $\begin{array}{l}\text { Bronchoalveolar lavage fluid } \\
\text { CD8+ T cells, \% }\end{array}$ & & & \\
CD8+CD122+T cells, \% & $7.61 \pm 0.11$ & $7.70 \pm 0.15^{\#}$ & $8.07 \pm 0.17^{*}$ \\
Lung tissue & $15.05 \pm 0.21$ & $14.61 \pm 0.14^{* \#}$ & $11.94 \pm 0.13^{*}$ \\
CD8+ T cells, \% & $34.65 \pm 0.13$ & $32.72 \pm 0.13^{\#}$ & $66.53 \pm 0.19^{*}$ \\
CD8+CD122+T cells, \% & $5.67 \pm 0.09$ & $4.63 \pm 0.09^{*}$ & $2.05 \pm 0.08^{*}$ \\
\hline
\end{tabular}

Results are expressed as mean $\pm \mathrm{SD}$

${ }^{*} P<0.05$ vs control group; ${ }^{\#} P<0.05$ vs ALI at $12 \mathrm{~h}$

CXCR3, CXCL10, and IFN- $\gamma$. At the same time, progression is associated with an increase in $\mathrm{CD} 8+\mathrm{T}$ cells and a decrease in $\mathrm{CD} 8+\mathrm{CD} 122+$ regulatory T cells in both BALF and lung tissue. These results are consistent with the known pro-inflammatory effects of CXCR3 and the known ability of $\mathrm{CD} 8+\mathrm{CD} 122+$ regulatory $\mathrm{T}$ cells to reduce inflammation by secreting IL-10. Taken together, our results provide preliminary evidence that restoring a balance between CXCR3 and IL-10 may help prevent or treat ALI.

CXCR3, a receptor for the inflammatory chemokines CXCL9, CXCL10, and CXCL11, is preferentially expressed on activated CD8+ T cells as well as Th1 cells and is thought to play a critical role in trafficking to sites of inflammation and in mediating biological functions such as
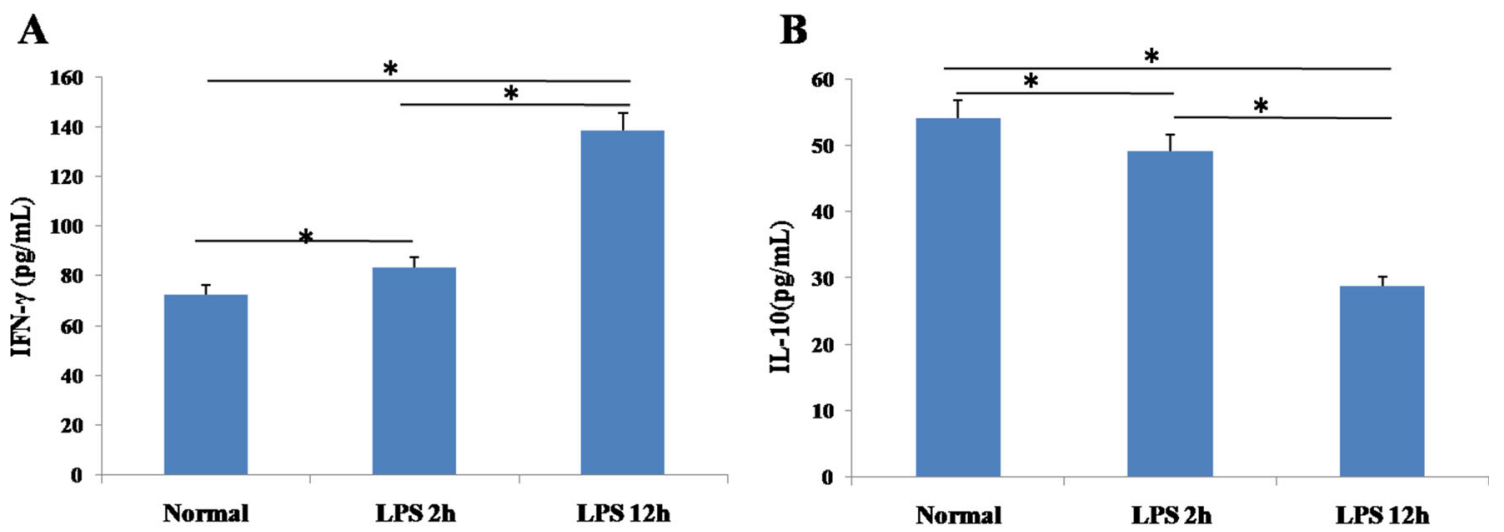

C

D
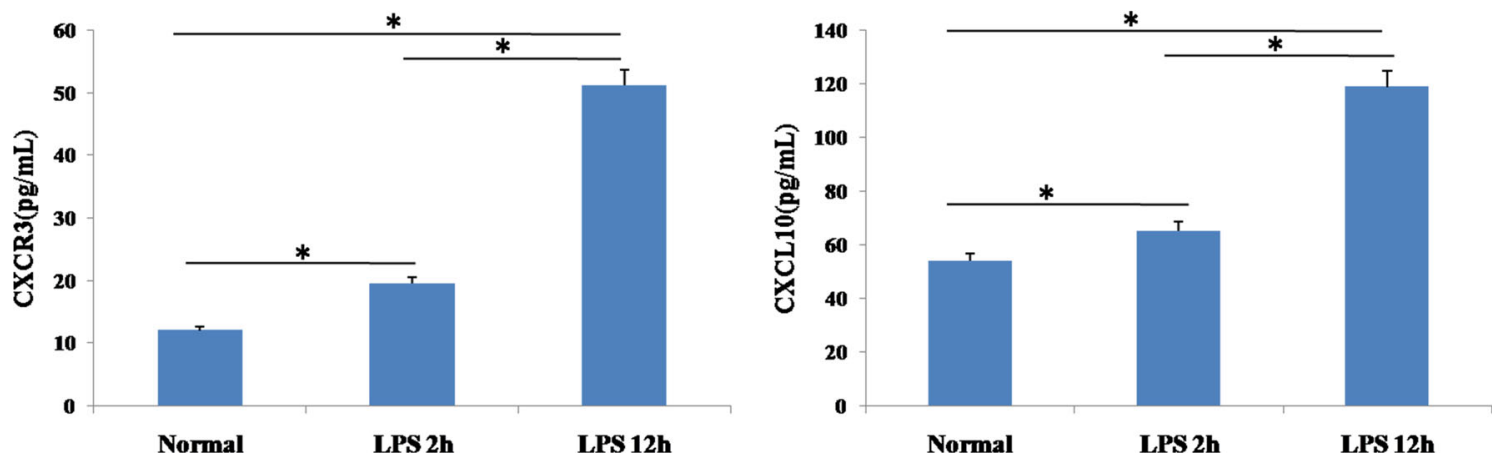

Fig. 3. ELISA determination of a IFN- $\gamma$, b IL-10, $\mathbf{c}$ CXCR3, and $\mathbf{d}$ CXCL10 in bronchoalveolar lavage fluid from control mice and mice with acute lung injury at 2 and $12 \mathrm{~h}$ after lipopolysaccharide (LPS) injection ( $n=8$ per group). Results are expressed as mean \pm SD. ${ }^{*} P<0.05$. 
Table 4. Concentrations of Inflammatory Cytokines and CXCL10 in Bronchoalveolar Lavage Fluid from Control Mice and Mice with Lipopolysaccharide-Induced Acute Lung Injury (ALI) After 2 or $12 \mathrm{~h}$

\begin{tabular}{llll}
\hline Factor & \multicolumn{3}{l}{ Concentration $(\mathrm{pg} / \mathrm{mL})$} \\
\cline { 2 - 4 } & Control $(n=8)$ & ALI at $2 \mathrm{~h}(n=8)$ & ALI at $12 \mathrm{~h}(n=8)$ \\
\hline IFN- $\gamma$ & $72.59 \pm 4.13$ & $83.42 \pm 4.71^{* \#}$ & $138.43 \pm 9.42^{*}$ \\
IL-10 & $54.17 \pm 3.24$ & $49.26 \pm 2.82^{* \#}$ & $28.77 \pm 2.05^{*}$ \\
CXCR3 & $11.99 \pm 1.13$ & $19.53 \pm 1.62^{* \#}$ & $51.13 \pm 2.42^{*}$ \\
CXCL10 & $53.91 \pm 4.31$ & $65.18 \pm 5.88^{* \#}$ & $118.75 \pm 7.18^{*}$ \\
\hline
\end{tabular}

Results are expressed as mean $\pm \mathrm{SD}$

$* P<0.05$ vs control group; ${ }^{\#} P<0.05$ vs ALI at $12 \mathrm{~h}$

cell migration and proliferation [7, 8]. CXCR3 and its ligands are involved in the pathogenesis of infection, autoimmune diseases, acute allograft rejection, and tumor growth [7, 9, 10]. During infection, injury, or immuno-inflammatory response, IFN $-\gamma$ strongly induces the expression of CXCR3 and CXCL10 primarily on activated T cells and NK cells [11, 12]. Several studies suggest that CXCR3, together with

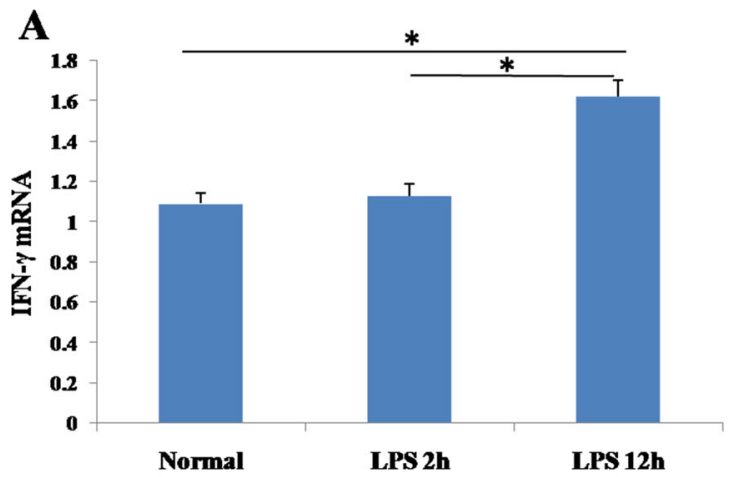

C

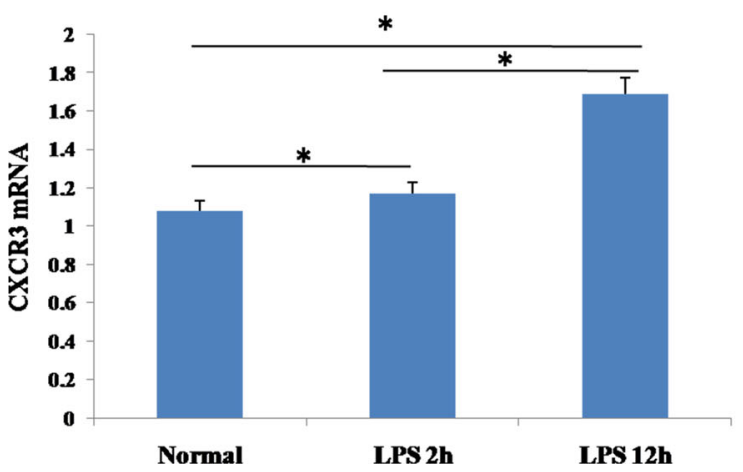

CXCL10, helps recruit $\mathrm{T}$ cells into the airways and lung parenchyma in ALI $[2,13,14]$. Excessive production of IFN- $\gamma$ and CXCL10 due to the presence of elevated numbers of $\mathrm{CD} 8+\mathrm{T}$ cells in lung is thought to contribute to chronic obstructive pulmonary disease (COPD) [15]: it appears that CXCL10 production in CD8+ T cells and bronchiolar epithelium triggers CXCR3 to recruit $\mathrm{T}$ lymphocytes, contributing to disease symptoms [16].These previous results in ALI and COPD are consistent with our observations of the joint proinflammatory effects of CXCR3 and CXCL10 in our mouse model of acute ALI. Taken together, the present and previous findings suggest that the CXCR3-CXCL10 interaction, by recruiting $\mathrm{T}$ cells to airways and lung parenchyma, plays a pivotal role in the pathogenesis and progression of ALI. This raises the question of whether lowering CXCR3 expression can slow ALI progression. Indeed, knocking out the CXCR3 gene in mice with experimentally induced acute pancreatitis has been shown to attenuate acute pulmonary injury [17].

The potent anti-inflammatory and immunosuppressive cytokine IL-10, a T-helper-2 (TH2) cytokine, helps control inflammation and modulate adaptive immune responses
B

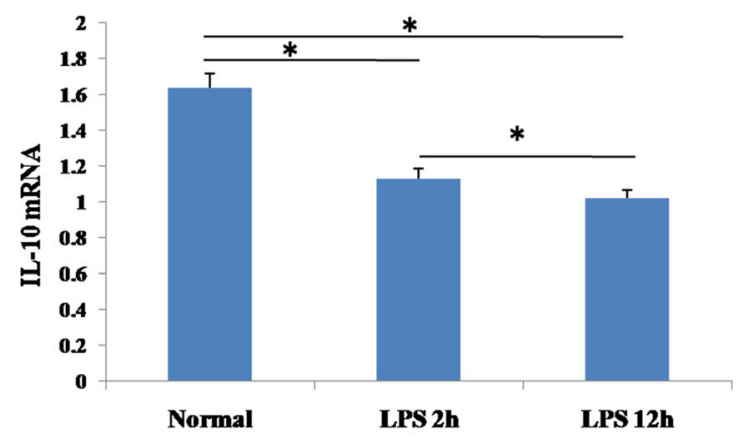

D

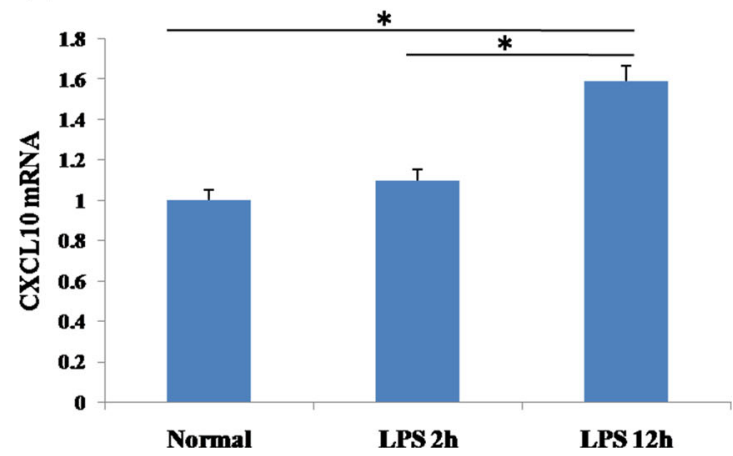

Fig. 4. RT-PCR quantitation of mRNA levels of a IFN- $\gamma$, $\mathbf{~ I L - 1 0 , ~} \mathbf{c}$ CXCR3, and $\mathbf{d}$ CXCL10 in lung tissues from control mice and mice with acute lung injury at 2 and $12 \mathrm{~h}$ after lipopolysaccharide (LPS) injection ( $n=8$ per group). Results are expressed as mean $\pm \mathrm{SD}$. ${ }^{*} P<0.05$. 
following tissue damage in numerous inflammatory diseases [18]. IL-10 in the liver modulates the inflammatory response and protects from collateral injury in chronic renal disease, colonitis, and cancer [19, 20]. IL-10 is also up-regulated during certain responses involving tolerant or regulatory $\mathrm{T}$ cells. A balance between IL-10 and IFN- $\gamma$ secreted by TH1 cells is thought to allow an effector response that is sufficiently strong but not excessive as in autoimmunity [20]. IL-10 levels are lower in patients with acute lung inflammation, asthma, COPD, or cystic fibrosis than in healthy individuals, and this deficiency may contribute to pathogenesis [21-23]. Our results demonstrating anti-inflammatory effects of IL-10 in a mouse model of acute ALI are consistent with the literature, and the present work provides the first clues that these effects depend on CXCR3. This extends previous studies suggesting that the anti-inflammatory effects of IL-10 are due in part to its ability to downregulate the expression of TNF and CXC-family chemokines y. Our findings add weight to the notion that adjusting IL-10 levels may be a useful immunomodulatory therapy in ALI.

Taken together, the results of the present experiments are consistent with a model in which concurrent up-regulation of CXRC3 and down-regulation of IL-10 help drive ALI. A major limitation of the current study is lack of intervention at the suspected molecular pathway and therefore the speculative nature of the conclusion. We appreciate the reviewer for this comment and have added discussion addressing such a limitation in the revised manuscript. Regardless, our findings that the reduction of $\mathrm{CD}^{+} \mathrm{CD} 122^{+}$regulatory $\mathrm{T}$ cells correlated with the increase in $\mathrm{CD}^{+} \mathrm{T}$ cells (as well as the changes in IL-10, IFN- $\gamma$, and CXCR3) suggest that $\mathrm{CD}^{+} \mathrm{CXCR}^{+}$regulatory $\mathrm{T}$ cells could alleviate ALI injury through stimulate the release of IL-10, inhibiting the production of IFN- $\gamma$, and inhibiting CXCR3 release. If proven by future studies, this could provide a novel pathway to modulate ALI response.

Compliance with Ethical Standards The authors declare no conflicts of interest. All experiments were conducted according to international and institutional guidelines for animal care, and the study protocol was approved by the Research Ethics Committee of Renmin Hospital, Wuhan University.

Conflict of Interest. The authors declare that they have no competing interests.

Funding. This work was supported by grants from the National Natural Science Foundation of China (nos. 81200058 and 81200389).
Open Access This article is distributed under the terms of the Creative Commons Attribution 4.0 International License (http://creativecommons.org/licenses/by/ 4.0/), which permits unrestricted use, distribution, and reproduction in any medium, provided you give appropriate credit to the original author(s) and the source, provide a link to the Creative Commons license, and indicate if changes were made.

\section{REFERENCES}

1. Matthay, M.A., L. Ware, and G.A. Zimmerman. 2012. The acute respiratory distress syndrome. The Journal of Clinical Investigation 122: 2731-2740.

2. Nie, L., R. Xiang, W. Zhou, B. Lu, D. Cheng, and J. Gao. 2008. Attenuation of acute lung inflammation induced by cigarette smoke in CXCR3 knockout mice. Respiratory Research 9: 82.

3. Ware, L.B. 2006. Pathophysiology of acute lung injury and the acute respiratory distress syndrome. Seminars in Respiratory and Critical Care Medicine 27: 337-349.

4. Shapiro, H., I. Kaqan, M. Shalita-chesner, J. Singer, and P. Singer. 2010. Inhaled aerosolized insulin: a "topical" anti-inflammatory treatment for acute lung injury and respiratory distress syndrome? Inflammation 33: 315-319.

5. Sun, J., Z.B. Han, W. Liao, S.G. Yang, Z. Yang, J. Yu, et al. 2001. Intrapulmonary delivery of human umbilical cord mesenchymal stem cells attenuates acute lung injury by expanding CD4+CD25+ Forkhead Boxp3 (FOXP3)+ regulatory T cells and balancing anti- and proinflammatory factors. Cellular Physiology and Biochemistry 27: 587596.

6. Endharti, A.T., M. Rifa'1, Z. Shi, Y. Fukuoka, Y. Nakahara, Y. Kawamoto, et al. 2005. Cutting edge: CD8+CD122+ regulatory $\mathrm{T}$ cells produce IL-10 to suppress IFN-gamma production and proliferation of CD8+ T cells. Journal of Immunology 175: 7093-7097.

7. Liu, L., M.K. Callahan, D. Huang, and R.M. Ransohoff. 2005. Chemokine receptor CXCR3: an unexpected enigma. Current Topics in Developmental Biology 68: 149-181.

8. Groom, J.R., and A.D. Luster. 2011. CXCR3 ligands: redundant, collaborative and antagonistic functions. Immunology and Cell Biology 89: 207-215.

9. Uppaluri, R., K.C. Sheehan, L. Wang, J.D. Bui, J.J. Brotman, B. Lu, et al. 2008. Prolongation of cardiac and islet allograft survival by a blocking hamster anti-mouse CXCR3 monoclonal antibody. Transplantation 86: 137-147.

10. Winkler, A.E., J.J. Brotman, M.E. Pittman, N.P. Judd, J.S. Jr Lewis, R.D. Schreiber, et al. 2011. CXCR3 enhances a T-cell-dependent epidermal proliferative response and promotes skin tumorigenesis. Cancer Research 71: 5707-5716.

11. Muller, M., S. Carter, M.J. Hofer, and I.L. Campbell. 2010. Review: the chemokine receptor CXCR3 and its ligands CXCL9, CXCL10 and CXCL11 in neuroimmunity - a tale of conflict and conundrum. Neuropathology and Applied Neurobiology 36: 368-387.

12. Nakajima, C., T. Mukai, N. Yamaguchi, Y. Morimoto, W.R. Park, M. Iwasaki, et al. 2002. Induction of the chemokine receptor CXCR3 on TCR-stimulated T cells: dependence on the release from persistent TCR-triggering and requirement for IFN-gamma stimulation. European Journal of Immunology 32: 1792-1801. 
13. Grumelli, S., D.B. Corry, L.Z. Song, L. Song, L. Green, J. Huh, et al. 2004. An immune basis for lung parenchymal destruction in chronic obstructive pulmonary disease and emphysema. PLoS Medicine 1: e8.

14. Ichikawa, A., K. Kuba, M. Morita, S. Chida, H. Tezuka, H. Hara, et al. 2013. CXCL10-CXCR3 enhances the development of neurophil-mediated fulminant lung injury of viral and nonviral origin. American Journal of Respiratory and Critical Care Medicine 187: 65-77.

15. D’Ambrosio, D., M. Mariani, P. Panina-Bordignon, and F. Sinigaglia. 2001. Chemokines and their receptors guiding T lymphocyte recruitment in lung inflammation. American Journal of Respiratory and Critical Care Medicine 164: 1266-1275.

16. Maeno, T., A.M. Houghton, P.A. Quintero, S. Grumelli, C.A. Owen, and S.D. Shapiro. 2007. CD8+ T cells are required for inflammation and destruction in cigarette smoke-induced emphysema in mice. Journal of Immunology 178: 8090-8096.

17. Shen, J., R. Wan, Z. Shen, J. Gao, X. Wang, L. Qian, et al. 2012. Chemokine receptor CXCR3 is involved in the acute pancreatitisassociated lung injury. Biomedicine Pharmacothe 66: 390-396.
18. Goodman, R.B., J. Pugin, J.S. Lee, and M.A. Matthay. 2003. Cytokine mediated inflammation in acute lung injury. Cytokine \& Growth Factor Reviews 14: 523-535.

19. Gaddi, P.J., M.J. Crane, M. Kamanaka, R.A. Flavell, et al. 2012. IL-10 mediated regulation of liver inflammation during acute murine cytomegalovirus infection. PloS One 7: e42850.

20. Dennnis, K.L., N.R. Blatner, F. Gounari, and K. Khazaie. 2013. Current status of interleukin-10 and regulatory T-cells in cancer. Current Opinion in Oncology 25: 637-645.

21. Bonfield, T.L., M.W. Konstan, P. Burfeind, J.R. Panuska, J.B. Hilliard, and M. Berger. 1995. Normal bronchial epithelial cells constitutively produce the anti-inflammatory cytokine interleukin-10, which is downregulated in cystic fibrosis. American Journal of Respiratory Cell and Molecular Biology 13: 257-261.

22. Takanashi, S., Y. Hasegawa, Y. Kanehira, K. Yamamoto, K. Fujimoto, K. Satoh, et al. 1999. Interleukin-10 level in sputum is reduced in bronchial asthma, COPD and in smokers. The European Respiratory Journal 14: 309-314.

23. Shanley, T.P., N. Vasi, and A. Deneberg. 2000. Regulation of chemokine expression by IL-10 in lung inflammation. Cytokine 12: 1054 1064 . 